\title{
Creating Creative Processes: A Workshop Demonstrating a Methodological Approach for Subjects Between the Sciences and the Arts
}

\author{
Carola Boehm \\ Music Department \& \\ Centre for Art and Design Research and Enterprise (CADRE) \\ Sport, Performing Arts and Leisure (SSPAL) \\ University of Wolverhampton, \\ Walsall University Campus, \\ Gorway Road, WALSALL, WS1 3BD \\ C.Boehm@wlv.ac.uk
}

\begin{abstract}
There is a lack of 'explicit education' of different modes of creativity and different methodologies for initiating creative processes. This is important for not only art practitioners, but specifically for developers of tools that support creative processes. The workshop, titled the "Creating-CreativeProcesses-Workshop", will demonstrate how a series of short exercises can provide a brief experience with a wide variety of distinct forms of creative processes, geared towards professionals that sit "inbetween" the sciences and the arts. Consequently participants experience a greater critical awareness of the methodologies and techniques chosen to create something artistic, the design of tools for creative productions, the understanding of creative processes in us humans, and the potential diversity of interaction between software tools and humans in the process of being creative.
\end{abstract}

\section{Categories and Subject Descriptors}

D.3.3 [Computer Applications]: Social and Behavioral sciences, arts and humanities, user interfaces

\section{Keywords}

Creativity, creative pull applications, interfaces for creative contexts, creative and performing arts applications.

\section{INTRODUCTION}

Having taught for a decade between the disciplines of music, computer science and electrical engineering, I have found that there is lack of 'explicit education' in the existence of different modes of creativity and different methodologies for initiating creative processes. To address this, I designed a workshop several years ago, specifically for postgraduate students coming from the three different disciplines. The workshop consists of a series of exercises that provide a brief experience with a wide variety of distinct forms of creative processes.

Besides my own pedagogical methodologies (Music), I have collated methods from artistic professionals which have integrated a targeted pedagogical approach to their teachings, i.e. I have drawn from workshops by Linda Weintraub (Modern/Emerging Art) [1,2], Liz Lochhead (Poetry) [3,4], and Greg Missingham (Architecture) [5,6].

(C) The Author 2008

Published by the British Computer Society
This submission consists of a $60-75$ min workshop, demonstrating it in practice, and will include the presentation of the context of this workshop and my experience in running it over the last 7 years in a variety of contexts, discipline and institutions.

\section{CREATIVITY, AN UNTOLD STORY}

The creative process is one of the most essential but until recently, also one of the least addressed components of artistic activity within the whole of the creative and performative arts. According to Sternberg [7], until 2000 references to creativity over 25 years account for ca only $0.5 \%$ of articles. Creativity is barely covered in textbooks or university departments although, since 2000 , one can perceive a slow but constant increase of research into creativity and creative processes and its acceptance as an area of research as well as an area for the facilitation of learning. There is an increase in and acceptance of education research, there is an increase in inter-, cross-, multi-, trans-disciplinary studies, and there is an increase in acceptance of practice-based methodologies in Higher Education. Traditionally in higher education, concentration was rather on technique, history and theory. Interdisciplinary programs, however, have the unique opportunity to initiate explorations of the origin and methodology of art production. Sternberg mentions that creativity is barely covered in psychology textbooks and university psychology departments rarely offer courses in creativity.

The notion of creative pull has been coined in the last years of the millennium, but what it has meant for application development and design methodologies has not been investigated very much [8].

Personally I have experienced that this situation is reflected in many music technology courses taught as part of our different degrees at many universities but also other disciplines that lie in the intersection of technology, science and art. To address this issue I have developed a small workshop that has been held for postgraduates and undergraduates. The workshop has been invited to other disciplines and other universities, such as Stage Design, Dance and Drams and others.

\section{THE WORKSHOP}

The series of small exercises, of which the workshop consists, provide a brief experience with a wide variety of distinct forms of creative processes by using only the simplest of utensils (paper, pencils, erasers, coloured pens, squared paper, pennies). 
Disciplines I have drawn upon are music, poetry, art and architecture.

The workshops is targeted to be populated by individuals from different disciplines. They can represents both individuals who are 'being trained' to design creative technology applications, and others, who will, in the future, be the ones opting to use them within a creative context. For both these groups, creativity tends to be important for the working process itself. But for both groups, I have found that there are narrow, preconceived notions of what types of creative processes are common and acceptable in their own field

Most individuals, through education and training, are used to only using the smallest number of creative methodologies (mostly improvisational modes for musicians and restrictive modes for scientists) and are often unaware of the full diversity of creative methodologies. This narrow view in the "non-digital world" can be seen to be mirrored in the software tools, as they tend to ignore the full diversity of creative methodology possible.

The workshop aims to demonstrate how many neglected alternative exist within the repertoire of human experience of artistic creation and is aimed at making individuals aware of the wide diversity of artistic methodology. Consequently participants experience a greater critical awareness of

- the methodologies and techniques chosen to create something artistic

- the design of tools for creative productions

- the understanding of creative processes in us humans

- the potential diversity of interaction between software tools and humans in the process of being creative.

A major inspiration for this work came from the contemporary art workshops of Linda Weintraub (Oberlin Henry R. Luce Professor in the Emerging Arts, New York), and many of her own exercises are integrated into the workshop. Her pedagogical practice integrates the "the intractably avant-garde and explores the manner in which (...) art works necessitate innovative pedagogical strategies."

Another inspiration were the creative writing workshops of Liz Lochead, the Scottish Poet and playwright, possibly best known for her stage version Bram Stoker's Dracula, but more recently for her published collection of poems "The Colour of Black and White: Poems 1984-2003". The exercises that I adapted from her workshop centred around the act of transferring sensual experiences to creative ones.

The latest inclusion of yet another discipline is that of architecture, with Australian architect Greg Missingham's studies on methodologies for working with many ideas at once. Beyond these three, some methodologies came from my own work within a music context.

This process for collecting methodologies for 'creating creative processes' is an ongoing process and it is planned to collaborate with more individuals from different disciplines to enlarge this selection indefinitely.

Headings of some of the exercises are: "Breaking preformed views of our world", "Using your destructive inclinations", "Introducing subjectivity through verbal communication", "Working with many ideas at once", "Symmetry and Repetition, "The unfulfilled self", "Master / Slave", "Directed Chance", "Democracy", "Imaginative Persona", "Division of Labour", "Multiple Exposure and Palimpsests", "Governing Metaphor", "Layering and Sequencing", "Suggestive Ambiguity", "Scoping an Audience", "Choosing a mission".

The workshop will demonstrate some of these exercises and the experience in holding these workshops will be presented and discussed. Further methodologies for initiating creative processes coming from other disciplines will be explored.

\section{REFERENCES}

[1] Weintraub, Linda. Making Contemporary Art, How today's artists think and work. Thames and Hudson, 2003.

[2] Weintraub, Linda. Workshop, Shared Visions Conference, Brighton, 2002.

[3] Lochhead, Liz. Creative Writing Workshop, University of Glasgow, 2006.

[4] Lochhead, Liz. The Colour of Black and White: Poems 1984-2003., Polygon, 2003.

[5] Missingham, Greig, Lattice Not Trees In The Black Forest: Too Many Ways of Dealing With Too Many Ideas, Systematically?, The 8th Symposium on Systems Research in the Arts: Music, Environmental Design and the Choreography of Space, Baden-Baden 2006.

[6] Missingham, Greig, Working with many ideas at once, The University of Melbourne, Melbourne, Australia, 2006.

[7] Robert J. Sternberg, (ed). Handbook of Creativity, Cambridge University Press, 1999

[8] John Patterson, Carola Boehm, "CIRCUS for Beginners", 14 pages, in: Boehm, Garcia and Schuter (eds.), CIRCUS 2001 - New Synergies in Digital Creativity. Proceedings of the Conference for Content Integrated Research in Creative User Systems. p. $182-193$, University of Glasgow, Glasgow, 2001, ISBN 0852617461. 